\title{
Adhesion G Protein-Coupled Receptor E1 Staining Method
}

National Cancer Institute

\section{Source}

National Cancer Institute. Adhesion G Protein-Coupled Receptor E1 Staining Method. NCI Thesaurus. Code C122846.

An immunohistochemical technique used to detect the presence of adhesion $\mathrm{G}$ proteincoupled receptor E1 in a tissue sample. 